\title{
Life-Cycle Cost Sensitivity to Battery-Pack Voltage of an HEV
}

\author{
John W. McKeever, Sujit Das, Leon M. Tolbert, Laura D. Marlino \\ Oak Ridge National Laboratory
}

Ashok Nedungadi

Southwest Research Institute

Copyright (C) 2000 Society of Automotive Engineers, Inc.

\begin{abstract}
*
A detailed component performance, ratings, and cost study was conducted on series and parallel hybrid electric vehicle (HEV) configurations for several battery pack and main electric traction motor voltages while meeting stringent Partnership for a New Generation of Vehicles (PNGV) power delivery requirements. A computer simulation calculated maximum current and voltage for each component as well as power and fuel consumption. These values defined the peak power ratings for each HEV drive system's electric components: batteries, battery cables, boost converter, generator, rectifier, motor, and inverter. To identify a superior configuration or voltage level, life cycle costs were calculated based on the components required to execute simulated drive schedules. These life cycle costs include the initial manufacturing cost of components, fuel cost, and battery replacement cost over the vehicle life.
\end{abstract}

\section{INTRODUCTION}

An HEV has a range of electrical power requirements usually supplied by a battery-pack or a fuel cell stack. The battery-pack is more common and is therefore a key component of today's HEVs. There is currently no standardization of the battery-pack voltage. This affects the material and manufacturing costs of the battery, electric motor, and controller.

\footnotetext{
*Prepared by the Oak Ridge National Laboratory, Oak Ridge, Tennessee 37831, managed by Lockheed Martin Energy Research Corporation for the U.S. Department of Energy under contract DE-AC05-96OR22464.

The submitted manuscript has been authored by a contractor of the U.S. Government under Contract No. DE-AC0596OR22464. Accordingly, the U.S. Government retains a nonexclusive, royalty-free license to publish from the contribution, or allow others to do so, for U.S. Government purposes.
}

A criterion for standardizing the battery-pack voltage would help the battery and traction motor vendors to optimize their products and lower their initial costs. During the HEV's lifetime, however, other life-cycle costs such as fuel costs and maintenance costs contribute significantly to the overall vehicle ownership cost. One consumer-friendly way to evaluate HEV voltage sensitivity is by comparing estimated life-cycle costs.

This study examines simulation data from Southwest Research Institute's Performance Assessment Toolbox for Hybrid Systems (PATHS) for series and parallel HEV configurations of 8 sets of drive system components operating with dc battery-pack voltages of $50,163,250$, 325 , and 450 volts and with ac electric traction motor voltages of 115,230 , and 320 volts. Life-cycle costs include the initial manufacturing cost of components, lifetime fuel cost, and maintenance cost. In this study, maintenance is limited to battery replacement every 2 years over the 10-year life of the HEV.

\section{HEV SIMULATION}

The series hybrid configuration receives its motive force from an electric traction motor, which receives its power only from a battery-pack. Its battery-pack is charged by a generator driven by an Internal Combustion (IC) engine, which fires when the state of charge (SOC) falls below $60 \%$ and stops when the SOC reaches $80 \%$. The series configuration is shown in Fig. 1.

The parallel hybrid configuration employs a more complex control strategy and may be driven by its electric traction motor and/or its IC engine. The control for the parallel configuration adds its own intelligence such as deciding if the drive system can meet the road load and energizing the IC engine if it cannot. The parallel configuration is shown in Fig. 2.

For both the series and parallel configurations studied the prime mover was a generic IC engine whose torque speed curves at full throttle were adjusted to deliver 40 $\mathrm{kW}$. 


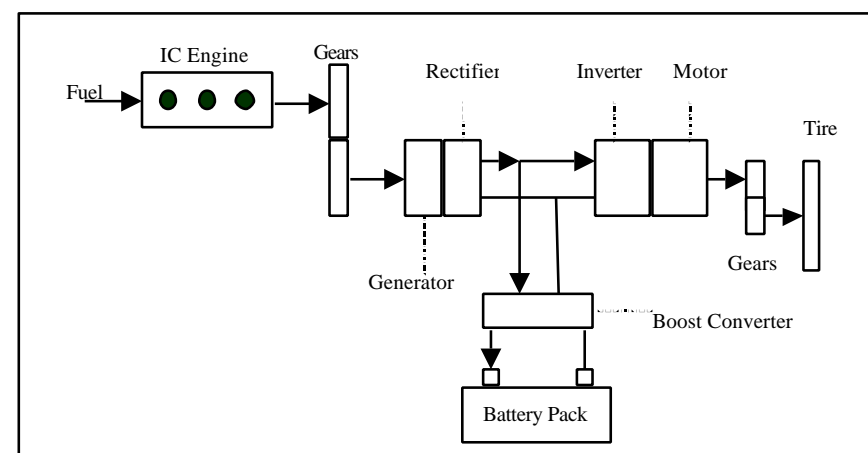

Figure 1. Series HEV Configuration

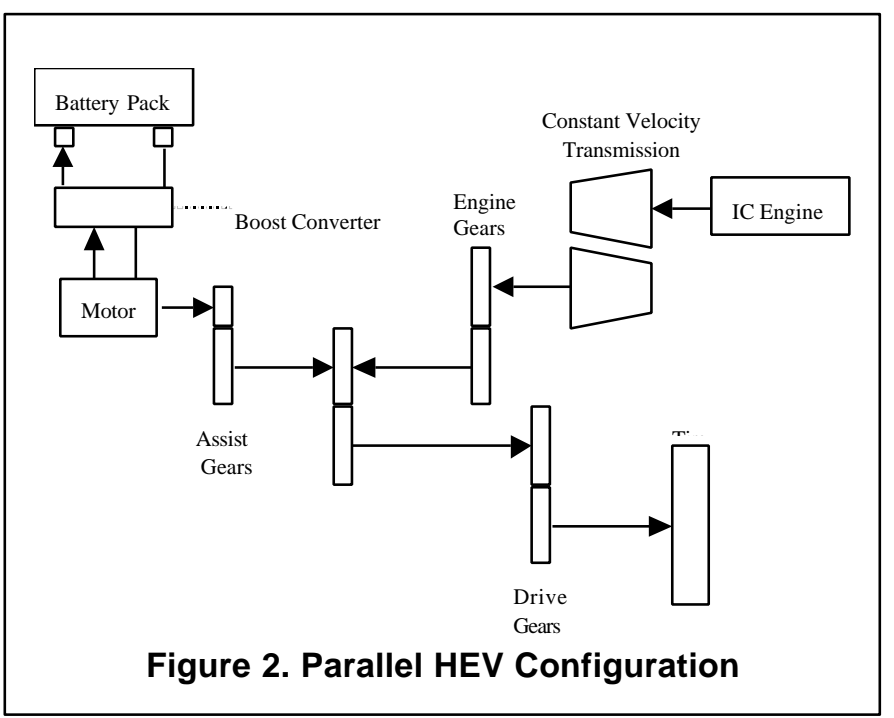

The number of batteries connected in series in one string depends upon the voltage level selected for the battery-pack. The number of strings was determined by PNGV requirements. The battery-pack of a series HEV should provide a peak power of $53 \mathrm{~kW}$ for two 23.4 second intervals of full power acceleration and deceleration over a time interval of 3 minutes. Similarly, the battery-pack of a parallel HEV should provide a peak power of $30 \mathrm{~kW}$ for two 23.4 second intervals of full power over a time interval of 3 minutes. For example, a $50 \mathrm{~V}$ battery-pack must supply $1060 \mathrm{~A}$ to provide $53 \mathrm{~kW}$. For a maximum current of $275 \mathrm{~A}$ from using a $12 \mathrm{~V}$ battery with a maximum current of $275 \mathrm{~A}$, requires a total of (1060/275) 4 parallel strings to supply the series HEV power. The battery size was selected to provide $275 \mathrm{~A}$ and was not charged when less current could still meet PNGV requirements. Consequently, all battery packs except those for Case 1 and 4 are oversized.

Lead acid batteries were modeled to be $80 \%$ efficient during charge and $100 \%$ efficient during discharge and were represented as a constant internal resistance in series with polarization and terminal resistance. Each battery in a string was assumed to have the same open circuit voltage and SOC. The SOC at the end of the run was always brought back to its initial value by running the generator (series HEV) or by backdriving the motor in regenerative mode with the wheels declutched (parallel HEV).
Three motor models were tailored so that their torquespeed curves and efficiency maps were identical to assure that, for a given configuration, the power delivered to the wheels would not depend on motor size. The peak power of the series HEV motors was $75 \mathrm{~kW}$, while the peak power of the parallel HEV motors was $37 \mathrm{~kW}$.

In addition to the drive inverter for the traction motor, several cases used a model of a boost converter to drive a high voltage motor with a low voltage battery-pack. The three components of a boost converter are a singlephase dc-ac high frequency inverter, a high frequency transformer, and a single-phase ac-dc rectifier. The efficiencies of the boost converter as well as the drive inverter $(1,2)$ were calculated as a function of load factor, which is the fraction of full load power for use in the simulation.

\section{PARAMETRIC VOLTAGE STUDY}

Eight sets of HEV drive components were devised to study the effects of battery-pack voltage variations on vehicle performance and life-cycle costs. Table 1 summarizes the experiments.

Table 1. Battery-Pack Voltage Variation Study Cases

\begin{tabular}{|c|c|c|c|c|c|}
\hline Case & $\begin{array}{c}\text { Battery } \\
\text { Pack } \\
\text { Volts }\end{array}$ & $\begin{array}{l}\text { Boost } \\
\text { Conv. }\end{array}$ & $\begin{array}{c}\text { AC } \\
\text { Motor } \\
\text { Volts }\end{array}$ & $\begin{array}{l}\text { Series HEV } \\
\# B / S \quad \# S\end{array}$ & $\begin{array}{l}\text { Parallel HEV } \\
\text { \#B/S \#S }\end{array}$ \\
\hline 1 & 50 & Yes & 320 & 4 & 4 \\
\hline 2 & 250 & Yes & 320 & $20 \quad 1$ & 201 \\
\hline 3 & 453 & $\mathrm{No}$ & 320 & 36 & $\begin{array}{ll}36 & 1 \\
\end{array}$ \\
\hline 4 & 50 & Yes & 115 & 4 & $\begin{array}{ll}4 & 3 \\
\end{array}$ \\
\hline 5 & 163 & No & 115 & $13 \quad 2$ & $\begin{array}{ll}13 & 1 \\
\end{array}$ \\
\hline 6 & 325 & No & 230 & $\begin{array}{ll}26 & 1 \\
\end{array}$ & $\begin{array}{ll}26 & 1 \\
\end{array}$ \\
\hline 7 & 125 & Yes & 230 & 102 & $10 \quad 1$ \\
\hline 8 & 325 & Yes & 320 & 261 & 261 \\
\hline
\end{tabular}

$\# \mathrm{~B} / \mathrm{S}$ is the number of batteries in series forming a string.

\#S is the number of strings forming parallel connections.

Cases $1,2,3$, and 8 explore the effect on performance of a high voltage traction motor by replacing batteries connected in series with a boost converter to match the battery pack voltage with that of the dc link to the inverter. In Case 3, 36 batteries eliminated the need for a boost converter, which consumes additional energy, but were heavy enough to reduce the maximum speed and affect other performance parameters. Cases 4 and 5 explored the effect of using a low voltage traction motor with different numbers of batteries and similarly Cases 6 and 7 explored the effect of using an intermediate voltage traction motor. 
FUEL CONSUMPTION

A useful way to evaluate the simulated performance is to examine the average energy deposited in each drive component divided by the energy content of the fuel, which gives the $\mathrm{kg}$ of fuel lost to inefficiencies in that component. The energy content of the fuel chosen for this study is $43,378 \mathrm{~kJ} / \mathrm{kg}$. The energy lost in a drive component is the product of the time interval and the difference between the time averaged power in and out. These values were provided by the simulations.

Tables 2 and 3 compare the fuel lost in the components of a series HEV and a parallel HEV as they traverse the urban route. Tables 4 and 5 compare the fuel lost in the components of a series HEV and a parallel HEV as they traverse the official highway route.

Table 2. Series HEV Fuel Losses during Federal Urban Driving Schedule

\begin{tabular}{|r|c|c|c|c|c|c|c|c|}
\hline & \multicolumn{7}{|c|}{ kg of fuel lost by: } & \\
\hline & $\begin{array}{c}\text { IC } \\
\text { Eng. }\end{array}$ & $\begin{array}{c}\text { Gen./ } \\
\text { Rect. }\end{array}$ & $\begin{array}{c}\text { Boost } \\
\text { Conv. }\end{array}$ & $\begin{array}{c}\text { Bat. } \\
\text { Pack }\end{array}$ & $\begin{array}{c}\text { Inv./ } \\
\text { Mot./ } \\
\text { Gen. }\end{array}$ & Gears & $\begin{array}{c}\text { Drive } \\
\text { Wheels }\end{array}$ & Total \\
\hline 1 & 0.868 & 0.011 & 0.084 & 0.092 & 0.043 & 0.007 & 0.075 & 1.17 \\
\hline 2 & 0.851 & 0.014 & 0.082 & 0.085 & 0.045 & 0.008 & 0.077 & 1.14 \\
\hline 3 & 0.595 & 0.017 & N/A & 0.073 & 0.053 & 0.008 & 0.085 & 0.83 \\
\hline 4 & 0.722 & 0.010 & 0.040 & 0.089 & 0.070 & 0.007 & 0.075 & 1.01 \\
\hline 5 & 0.761 & 0.021 & N/A & 0.109 & 0.075 & 0.008 & 0.078 & 1.05 \\
\hline 6 & 0.555 & 0.016 & N/A & 0.075 & 0.037 & 0.008 & 0.077 & 0.77 \\
\hline 7 & 0.866 & 0.016 & 0.083 & 0.100 & 0.035 & 0.008 & 0.076 & 1.18 \\
\hline 8 & 0.876 & 0.023 & 0.078 & 0.099 & 0.048 & 0.008 & 0.079 & 1.21 \\
\hline
\end{tabular}

Table 3. Parallel HEV Fuel Losses

during Federal Urban Schedule

\begin{tabular}{|r|c|c|c|c|c|c|c|}
\hline & \multicolumn{7}{|c|}{ kg of fuel lost by: } \\
\hline Case & $\begin{array}{c}\text { IC } \\
\text { Eng. }\end{array}$ & $\begin{array}{c}\text { Mot./ } \\
\text { Inv. }\end{array}$ & $\begin{array}{c}\text { Boost } \\
\text { Conv. }\end{array}$ & $\begin{array}{c}\text { Bat. } \\
\text { Pack }\end{array}$ & $\begin{array}{c}\text { CVT } \\
\text { axles }\end{array}$ & $\begin{array}{c}\text { Drive } \\
\text { Wheels }\end{array}$ & Total \\
\hline 1 & 0.716 & 0.026 & 0.022 & 0.032 & 0.084 & 0.111 & 0.99 \\
\hline 2 & 1.069 & 0.052 & 0.045 & 0.044 & 0.155 & 0.108 & 1.47 \\
\hline 3 & 0.769 & 0.050 & N/A & 0.030 & 0.110 & 0.100 & 1.06 \\
\hline 4 & 0.769 & 0.036 & 0.021 & 0.033 & 0.094 & 0.106 & 1.06 \\
\hline 5 & 0.779 & 0.049 & N/A & 0.041 & 0.098 & 0.106 & 1.07 \\
\hline 6 & 0.689 & 0.046 & N/A & 0.032 & 0.091 & 0.094 & 0.95 \\
\hline 7 & 0.746 & 0.036 & 0.032 & 0.037 & 0.092 & 0.085 & 1.03 \\
\hline 8 & 0.988 & 0.046 & 0.044 & 0.040 & 0.145 & 0.098 & 1.36 \\
\hline
\end{tabular}

Table 4. Series HEV Fuel Losses during Federal Highway Driving Schedule

\begin{tabular}{|c|c|c|c|c|c|c|c|c|}
\hline & \multicolumn{7}{|c|}{ Kg of fuel lost by: } & \multirow[b]{2}{*}{ Total } \\
\hline Case & $\begin{array}{c}\text { IC } \\
\text { Eng. }\end{array}$ & $\begin{array}{l}\text { Gen./ } \\
\text { Rect. }\end{array}$ & $\begin{array}{l}\text { Boost } \\
\text { Conv. }\end{array}$ & $\begin{array}{l}\text { Bat. } \\
\text { Pack }\end{array}$ & $\begin{array}{l}\text { Inv./ } \\
\text { Mot./ } \\
\text { Gen. }\end{array}$ & Gears & $\begin{array}{c}\text { Drive } \\
\text { Wheels }\end{array}$ & \\
\hline 1 & 1.044 & 0.019 & 0.056 & 0.113 & 0.021 & 0.007 & 0.153 & 1.42 \\
\hline 2 & 0.990 & 0.019 & 0.059 & 0.087 & 0.021 & 0.007 & 0.155 & 1.35 \\
\hline 3 & 0.858 & 0.023 & N/A & 0.083 & 0.024 & 0.008 & 0.166 & 1.17 \\
\hline 4 & 1.075 & 0.021 & 0.037 & 0.120 & 0.055 & 0.007 & 0.152 & 1.47 \\
\hline 5 & 1.032 & 0.036 & N/A & 0.116 & 0.059 & 0.008 & 0.160 & 1.42 \\
\hline 6 & 0.891 & 0.018 & N/A & 0.097 & 0.022 & 0.008 & 0.157 & 1.19 \\
\hline 7 & 0.996 & 0.019 & 0.059 & 0.100 & 0.020 & 0.007 & 0.155 & 1.36 \\
\hline 8 & 1.069 & 0.040 & 0.070 & 0.096 & 0.022 & 0.008 & 0.159 & 1.47 \\
\hline
\end{tabular}

Early examination of simulated power flowing bidirectionally through the boost converter revealed that the efficiency was quite low. Further examination revealed that much of the time the boost converter does not operate near its design limit, which means that its
Table 5. Parallel HEV Fuel Losses

during Federal Highway Schedule

\begin{tabular}{|c|c|c|c|c|c|c|c|}
\hline & \multicolumn{6}{|c|}{$\mathrm{kg}$ of fuel lost by: } & \multirow[b]{2}{*}{ Total } \\
\hline Case & $\begin{array}{c}\text { IC } \\
\text { Eng. }\end{array}$ & $\begin{array}{l}\text { Mot./ } \\
\text { Inv. }\end{array}$ & $\begin{array}{l}\text { Boost } \\
\text { Conv. }\end{array}$ & $\begin{array}{l}\text { Bat. } \\
\text { Pack }\end{array}$ & $\begin{array}{l}\text { CVT } \\
\text { axles }\end{array}$ & $\begin{array}{c}\text { Drive } \\
\text { Wheels }\end{array}$ & \\
\hline 1 & 0.552 & 0.007 & 0.012 & 0.017 & 0.026 & 0.164 & 0.77 \\
\hline 2 & 1.510 & 0.033 & 0.043 & 0.055 & 0.215 & 0.238 & 2.09 \\
\hline 3 & 1.236 & 0.038 & N/A & 0.050 & 0.208 & 0.172 & 1.70 \\
\hline 4 & 0.541 & 0.012 & 0.011 & 0.016 & 0.026 & 0.158 & 0.76 \\
\hline 5 & 0.963 & 0.031 & N/A & 0.044 & 0.117 & 0.184 & 1.34 \\
\hline 6 & 0.924 & 0.028 & N/A & 0.038 & 0.134 & 0.159 & 1.29 \\
\hline 7 & 0.799 & 0.019 & 0.024 & 0.033 & 0.087 & 0.155 & 1.11 \\
\hline 8 & 1.055 & 0.028 & 0.021 & 0.037 & 0.158 & 0.163 & 1.46 \\
\hline
\end{tabular}

load factor is low, explaining its low efficiency. The impact of this on overall performance may be determined by examining the boost converter columns in Tables 2 through 5.

The urban $(12 \mathrm{~km})$ and the highway $(16.5 \mathrm{~km})$ schedules may be viewed as two energy sinks, each of which consume from the drive wheels a bounding minimum energy when a "properly" configured and controlled HEV traverses it. When the simulations are examined to determine the least fuel delivered to the drive wheels, that value may be considered an estimate of the bounding minimum. Estimates of the minima for the urban and highway schedules are 0.075 (Table 2) and $0.152 \mathrm{~kg}$ fuel (Table 4) respectively. The difference between the fuel actually delivered to the drive wheels and the estimate of the bounding minimum is a penalty characteristic of the control system's ability to efficiently move the vehicle through the schedule's accelerations and decelerations. We define this as the control penalty, i.e., the control penalty for the Case 1 parallel HEV (Table 3) traversing the urban schedule is $0.036 \mathrm{~kg}$ fuel

Likewise, the fuel consumption of all components except for the drive wheels has a bounding minimum, which may be estimated from data in Tables 2 through 5 . We define the difference between these values and their estimated minimum as the configuration penalty. There may be more components to consume energy or excessive energy may be consumed in certain components. Estimates of the minima for the urban and highway schedules are 0.693 and $0.602 \mathrm{~kg}$ fuel respectively. The configuration penalty for the Case 1 parallel HEV (Table 3 ) configuration traversing the urban schedule is $0.186 \mathrm{~kg}$ fuel.

The sum of the penalties is a performance indicator for each case within a schedule. Table 6 presents configuration and control fuel consumption penalties for comparison.

For the urban schedule, Case 6, which drives an intermediate voltage motor and uses no boost converter, is the clear winner for the series HEV and a good performer for the parallel HEV with total configuration plus control penalty values of $0.002 \mathrm{~kg}$ and $0.182 \mathrm{~kg}$ respectively. The Case 3 series HEV, which drives the highest voltage motor and uses no boost converter, performs very well with a penalty of $0.062 \mathrm{~kg}$. 
Table 6. Fuel Consumption Penalties

Total kg Urban Fuel $=0.693+0.075+$ Configuration Penalty + Control Penalty Total kg Highway Fuel $=0.602+\mathbf{0 . 1 5 2}+$ Configuration Penalty + Control Penalty

\begin{tabular}{|c|c|c|c|c|c|c|c|}
\hline & \multicolumn{3}{|c|}{ Urban Penalty, kg fuel } & \multicolumn{3}{|c|}{ Highway Penalty, kg fuel } & \multirow[b]{2}{*}{$\begin{array}{l}\text { Sum of } \\
\text { Sums, } \\
\text { kg Fuel }\end{array}$} \\
\hline Case & Configuration & Control & Sum & Configuration & Control & Sum & \\
\hline \multicolumn{8}{|l|}{ Series } \\
\hline 1 & .402 & 0 & .402 & .665 & .001 & .666 & 1.068 \\
\hline 2 & .370 & .002 & .372 & .593 & .003 & .596 & .968 \\
\hline 3 & .052 & .010 & .062 & .402 & .014 & .416 & .478 \\
\hline 4 & 242 & 0 & .242 & .716 & 0 & .716 & .958 \\
\hline 5 & 279 & .003 & .281 & .658 & .008 & .666 & .948 \\
\hline 6 & 0 & .002 & .002 & .431 & .005 & .436 & .438 \\
\hline 7 & .411 & .001 & .412 & .603 & .003 & .606 & 1.018 \\
\hline 8 & .438 & .004 & .442 & .709 & .007 & .716 & 1.168 \\
\hline \multicolumn{8}{|l|}{ Parallel } \\
\hline 1 & .186 & .036 & .222 & .004 & .012 & .016 & .238 \\
\hline 2 & .669 & .033 & .702 & 1.250 & .086 & 1.336 & 2.038 \\
\hline 3 & .267 & .025 & .292 & .926 & .020 & .946 & 1.238 \\
\hline 4 & 261 & .031 & .292 & 0 & .006 & .006 & .298 \\
\hline 5 & 271 & .031 & .302 & .554 & .032 & .586 & .888 \\
\hline 6 & .163 & .019 & .182 & .529 & .007 & .536 & .718 \\
\hline 7 & .252 & .010 & .262 & .353 & .003 & .356 & .618 \\
\hline 8 & .569 & .023 & .592 & .695 & .011 & .706 & 1.298 \\
\hline
\end{tabular}

The highway data exhibit more scatter. Cases 1 and 4 are clear winners for the parallel HEV with total penalty values of 0.016 and $0.006 \mathrm{~kg}$ respectively, but not for the series HEV, whose values were near $0.7 \mathrm{~kg}$. Both cases use a boost converter but Case 1 drives the highest voltage motor while Case 4 drives the lowest voltage motor. Case 3 was the winner for the series HEV with a total penalty of $0.416 \mathrm{~kg}$.

For equally weighted urban and highway schedules the overall winner is parallel HEV Case 1.

For the parallel configuration, significant energy comes directly from the IC engine, which is in parallel with the traction motor. Consequently, this energy is not involved in any battery regeneration with its attendant losses. For this reason, the average energy consumed by the battery packs in the series HEV, $0.095 \mathrm{~kg}$ fuel, was greater than that for the parallel HEV, $0.036 \mathrm{~kg}$ fuel by a factor of 2.6.

\section{HEV COMPONENT RATINGS}

The computer simulation calculates the voltage and current in the drive components of eight sets of series HEVs and parallel HEVs as they traverse Federal Urban and Highway Driving Schedules. The initial component costs depend upon the power that must pass through them. Battery-pack and inverter dc bus voltages do not change significantly. Table 7 summarizes the important voltages and maximum currents for the drive components in the series HEV. Each component must survive the maximum current it will conduct, which is extracted from the simulation output. Table 8 summarizes the important voltages and maximum currents for the parallel HEV.
Table 7. Voltage and Maximum Currents in Drive of Series HEV

\begin{tabular}{|c|c|c|c|c|c|c|c|}
\hline & \multicolumn{2}{|c|}{ Battery-Pack } & \multicolumn{2}{|c|}{ Boost Conv. } & \multirow{2}{*}{$\begin{array}{l}\text { Gen./ } \\
\text { Rect. } \\
\text { Max } \\
\text { Amps }\end{array}$} & \multicolumn{2}{|c|}{ Inv./Mot./Gen. } \\
\hline Case & $\begin{array}{l}\text { Avg. } \\
\text { Volts }\end{array}$ & $\begin{array}{l}\text { Max } \\
\text { Amps }\end{array}$ & $\begin{array}{c}\text { Max } \\
\text { Amps } \\
\text { In }\end{array}$ & $\begin{array}{c}\text { Max } \\
\text { Amps } \\
\text { Out }\end{array}$ & & $\begin{array}{c}\text { DC } \\
\text { Link } \\
\text { Volts }\end{array}$ & $\begin{array}{l}\text { Max } \\
\text { Amps }\end{array}$ \\
\hline \multicolumn{8}{|l|}{ Urban } \\
\hline 1 & 53 & 262 & 1048 & 190 & 39 & 453 & 190 \\
\hline 2 & 251 & 221 & 221 & 159 & 39 & 453 & 159 \\
\hline 3 & 447 & 142 & N/A & N/A & 38 & 453 & 142 \\
\hline 4 & 53 & 267 & 1068 & 118 & 107 & 163 & 273 \\
\hline 5 & 163 & 197 & N/A & N/A & 105 & 163 & 394 \\
\hline 6 & 323 & 193 & N/A & N/A & 52 & 325 & 193 \\
\hline 7 & 128 & 214 & 428 & 213 & 54 & 325 & 213 \\
\hline 8 & 323 & 177 & 177 & 159 & 28 & 453 & 159 \\
\hline \multicolumn{8}{|c|}{ Highway } \\
\hline 1 & 57 & 231 & 924 & 106 & 39 & 453 & 73 \\
\hline 2 & 252 & 174 & 174 & 104 & 39 & 453 & 76 \\
\hline 3 & 448 & 125 & N/A & N/A & 38 & 453 & 125 \\
\hline 4 & 57 & 217 & 866 & 248 & 107 & 163 & 220 \\
\hline 5 & 164 & 143 & N/A & N/A & 126 & 163 & 285 \\
\hline 6 & 324 & 161 & N/A & N/A & 48 & 325 & 161 \\
\hline 7 & 129 & 171 & 342 & 144 & 54 & 325 & 104 \\
\hline 8 & 324 & 141 & 141 & 118 & 39 & 453 & 156 \\
\hline
\end{tabular}

Some judgement was required to determine the power rating of each component. The rating was dictated by catalog availability of each component.

The maximum power that must be delivered by the generator is the product of the maximum current through the generator (and rectifier) and the inverter bus voltage.

The voltage rating of the series HEV rectifier depends upon the next higher catalog rating. For example, the next higher rectifier rating above an inverter bus voltage of $453 \mathrm{~V}$ is $600 \mathrm{~V}$ and the next higher inverter rating above a bus voltage of $325 \mathrm{~V}$ is $450 \mathrm{~V}$. The product of the catalog rectifier voltage rating and the maximum current through the rectifier determines its rated peak power. 
Table 8. Voltage and Maximum Currents in Drive of Parallel HEV

\begin{tabular}{|c|c|c|c|c|c|c|}
\hline & \multicolumn{2}{|c|}{ Battery-Pack } & \multicolumn{2}{|c|}{ Boost Conv. } & \multicolumn{2}{|c|}{ Inv./Mot./Gen. } \\
\hline Case & $\begin{array}{l}\text { Avg. } \\
\text { Volts }\end{array}$ & $\begin{array}{l}\text { Max } \\
\text { Amps }\end{array}$ & $\begin{array}{c}\text { Max } \\
\text { Amps } \\
\text { In }\end{array}$ & $\begin{array}{c}\text { Max } \\
\text { Amps } \\
\text { Out }\end{array}$ & $\begin{array}{c}\text { DC } \\
\text { Link } \\
\text { Volts }\end{array}$ & $\begin{array}{l}\text { Max } \\
\text { Amps }\end{array}$ \\
\hline \multicolumn{7}{|c|}{ Urban } \\
\hline 1 & 51 & 174 & 523 & 45 & 453 & 45 \\
\hline 2 & 249 & 196 & 196 & 84 & 453 & 84 \\
\hline 3 & 447 & 69 & N/A & N/A & 453 & 69 \\
\hline 4 & 51 & 180 & 540 & 129 & 163 & 129 \\
\hline 5 & 163 & 266 & N/A & N/A & 163 & 266 \\
\hline 6 & 323 & 97 & N/A & N/A & 325 & 97 \\
\hline 7 & 127 & 356 & 356 & 108 & 325 & 108 \\
\hline 8 & 323 & 102 & 102 & 58 & 453 & 58 \\
\hline \multicolumn{7}{|c|}{ Highway } \\
\hline 1 & 53 & 214 & 642 & 54 & 453 & 54 \\
\hline 2 & 251 & 149 & 149 & 64 & 453 & 64 \\
\hline 3 & 448 & 95 & N/A & N/A & 453 & 95 \\
\hline 4 & 52 & 213 & 639 & 156 & 163 & 156 \\
\hline 5 & 167 & 257 & N/A & N/A & 163 & 257 \\
\hline 6 & 324 & 100 & N/A & N/A & 325 & 100 \\
\hline 7 & 130 & 301 & 302 & 92 & 325 & 92 \\
\hline 8 & 324 & 92 & 92 & 68 & 453 & 68 \\
\hline
\end{tabular}

Because the boost converter and the drive inverter are attached to the inverter bus, which sees voltages from 163 to $453 \mathrm{~V}$, it seemed reasonable to fix the rated voltage of their devices at $600 \mathrm{~V}$. For the boost converter, the current ratings on the low and high side were the next higher catalog current rating for an IGBT. For example, the next higher current rating above $1048 \mathrm{~A}$ is $1200 \mathrm{~A}$ on the low side and the next higher current rating above $190 \mathrm{~A}$ is $200 \mathrm{~A}$ on the high side. The maximum current rating of the boost converter is the sum of its maximum high and low side current ratings. The product of the maximum current rating of the boost converter and $600 \mathrm{~V}$ is the peak rated power of the boost converter. Similarly, the inverter's peak power is the product of its maximum current and 600V. The peak power of the motors was modeled at $75 \mathrm{~kW}$ and $37 \mathrm{~kW}$ for the series and parallel HEV respectively.

\section{LIFE-CYCLE COST ESTIMATES}

This life-cycle cost analysis considers the initial component costs, the fuel costs, and the primary maintenance cost, which is replacement of the battery pack every two years over the life of the vehicle. The HEV wheels travel $12 \mathrm{~km}$ during the Federal Urban Driving Schedule and $16.5 \mathrm{~km}$ during the Federal Highway Driving Schedule representing a one-way trip to work. If this drive is made twice a day for 365 days each year over the 10 year life of the vehicle, the total distance is 129,000 miles. Fuel is assumed to be $\$ 1$ per gallon $(0.352 \$ / \mathrm{kg})$ for the estimates of lifetime fuel costs.

The initial component manufacturing costs for the series HEV include the batteries and connecting cables, the generator/rectifier, the boost converter, and the inverter/motor/regeneration system. The parallel HEV has no generator/rectifier system. Peak power values are transformed into component costs using cost equations from vendors and from the Institute for Transportation Studies at the University of California at Davis (3).

\section{BATTERY AND CABLE COSTS}

The cost of a $12 \mathrm{~V}$ lead-acid Hawker Genesis battery in quantities of 25,000 is about $\$ 80$. The cable length is determined by the battery stack for each case. Reasonable battery stacks were assumed and the length of cable required to connect the terminals was increased by $2 \mathrm{ft}$ to accommodate connection to the boost converter or inverter bus. The cost per foot of polyvinyl chloride (PVC) extruded Litz cable rated at $130 \mathrm{~A}$ is $\$ 0.70$ per ft. Connector costs were not included.

\section{RECTIFIER}

The formula for the rectifier cost is,

$$
\text { Rectifier cost }=\$ 5 \times \text { kWpeak. }
$$

\section{INVERTER}

The Department of Energy's (DOE's) Automotive Integrated Power Module (AIPM) has provided cost functions for inverters that drive ac induction motors (3). The formula used for this study is a combination of the material costs associated with production rates of 20,000 units per year and the lower manufacturing costs associated with rates of 200,000 units per year. The formula for inverter cost is,

$$
\text { Inverter cost }=\$ 418+\$ 7.60 \times \mathrm{kW} \text { peak. }
$$

\section{BOOST CONVERTER}

The material cost of the boost converter was extracted (3) from Argonne National Laboratory's (ANL's) estimates of the near term material costs of an inverter, $\$ 775$, reduced by the cost of the control components, $\$ 445$. The reasoning is that the boost converter can be controlled with the same control components as the inverter. To obtain a material cost on the same basis as the AIPM inverter material cost, $\$ 418$ was scaled by $445 / 775$. The formula for the boost converter cost is,

$$
\text { Boost Converter cost }=\$ 240+\$ 7.60 \times \mathrm{kW} \text { peak. }
$$

\section{GENERATOR AND MOTOR}

Generator and three-phase motor costs were determined as an average of three estimates from the Office of Technology Assessment, Rajashekara and Martin, and the University of California at Davis (3). The formula for the generator and motor cost is,

$$
\text { Motor Cost }=\$ 33.33+\$ 10.6 \times \mathrm{kW} \text { peak. }
$$

Tables 9 and 10 contain the initial component costs. Table 11 compares the battery-pack costs, the initial 
drive system costs, the fuel costs, the battery replacement costs, and the total life-cycle costs. The winner appears to be the arrangement for the parallel configuration that uses no boost converter and the smallest motor.

Table 9. Initial HEV Battery-Pack, Generator, and Rectifier Costs

\begin{tabular}{|c|c|c|c|c|c|c|c|c|c|}
\hline & \multicolumn{2}{|c|}{ Battery Cables } & \multicolumn{2}{|c|}{ Battery-Pack } & \multicolumn{2}{|c|}{ Generator } & \multicolumn{3}{|c|}{ Rectifier } \\
\hline Case & $\begin{array}{c}\text { Length, } \\
\mathrm{ft}\end{array}$ & $\underset{\$}{\text { Cost, }}$ & $\begin{array}{l}\text { No. } \\
\text { Bats. }\end{array}$ & $\underset{\$}{\text { Cost, }}$ & $\begin{array}{l}\text { Peak } \\
\text { Power, } \\
\text { kW }\end{array}$ & $\underset{\$}{\text { Cost }}$ & $\begin{array}{c}\text { Rated } \\
\text { Current } \\
\text { Amps }\end{array}$ & $\begin{array}{c}\text { Peak } \\
\text { Power, } \\
\text { kW }\end{array}$ & $\underset{\$}{\text { Cost }}$ \\
\hline \multicolumn{10}{|c|}{ Series } \\
\hline 1 & 22 & $\$ 15$ & 16 & $\$ 1,282$ & 17.7 & $\$ 221$ & 50 & 30.0 & $\$ 150$ \\
\hline 2 & 23 & $\$ 16$ & 20 & $\$ 1,603$ & 17.7 & $\$ 221$ & 50 & 30.0 & $\$ 150$ \\
\hline 3 & 39 & $\$ 27$ & 36 & $\$ 2,885$ & 17.2 & $\$ 216$ & 50 & 30.0 & $\$ 150$ \\
\hline 4 & 22 & $\$ 15$ & 16 & $\$ 1,282$ & 17.4 & $\$ 218$ & 150 & 67.5 & $\$ 338$ \\
\hline 5 & 30 & $\$ 21$ & 26 & $\$ 2,083$ & 20.5 & $\$ 251$ & 150 & 67.5 & $\$ 338$ \\
\hline 6 & 29 & $\$ 20$ & 26 & $\$ 2,083$ & 16.9 & $\$ 212$ & 75 & 33.8 & $\$ 169$ \\
\hline 7 & 24 & $\$ 17$ & 20 & $\$ 1,603$ & 17.6 & $\$ 220$ & 75 & 33.8 & $\$ 169$ \\
\hline 8 & 29 & $\$ 20$ & 26 & $\$ 2,083$ & 17.7 & $\$ 221$ & 50 & 30.0 & $\$ 150$ \\
\hline \multicolumn{10}{|c|}{ Parallel } \\
\hline 1 & 17 & $\$ 12$ & 12 & $\$ 962$ & & & & & \\
\hline 2 & 23 & $\$ 16$ & 20 & $\$ 1,603$ & & & & & \\
\hline 3 & 39 & $\$ 27$ & 36 & $\$ 2,885$ & & & & & \\
\hline 4 & 17 & $\$ 12$ & 12 & $\$ 962$ & & & & & \\
\hline 5 & 16 & $\$ 11$ & 13 & $\$ 1,042$ & & & & & \\
\hline 6 & 29 & $\$ 20$ & 26 & $\$ 2,083$ & & & & & \\
\hline 7 & 13 & $\$ 9$ & 10 & $\$ 801$ & & & & & \\
\hline 8 & 29 & $\$ 20$ & 26 & $\$ 2,083$ & & & & & \\
\hline
\end{tabular}

Table 10. Initial HEV Boost Converter, Inverter, and Three-Phase Traction Motor and Total Drive System Costs

\begin{tabular}{|c|c|c|c|c|c|c|c|c|c|}
\hline \multirow[b]{3}{*}{ Case } & \multicolumn{4}{|c|}{ Boost Converter } & \multicolumn{2}{|c|}{$\begin{array}{l}\text { Inverter/ } \\
\text { Controller }\end{array}$} & \multicolumn{2}{|c|}{ 3-phase Motor } & \multirow{3}{*}{$\begin{array}{c}\text { Total } \\
\text { Drive } \\
\text { System } \\
\text { Cost, } \\
\$\end{array}$} \\
\hline & \multicolumn{2}{|c|}{$\begin{array}{c}600 \text { V IGBT } \\
\text { Current Rating, } \\
\text { Amps }\end{array}$} & \multirow{2}{*}{$\begin{array}{l}\text { Rated } \\
\text { Input } \\
\text { plus } \\
\text { Output } \\
\text { Power, } \\
\text { kW }\end{array}$} & \multirow[b]{2}{*}{$\begin{array}{c}\text { Cost, } \\
\$\end{array}$} & \multirow{2}{*}{$\begin{array}{c}600 \mathrm{~V} \\
\text { IGBT } \\
\text { Rated } \\
\text { Current, } \\
\text { Amps }\end{array}$} & \multirow[b]{2}{*}{$\begin{array}{c}\text { Cost, } \\
\$\end{array}$} & \multirow{2}{*}{$\begin{array}{l}\text { Peak } \\
\text { Power, } \\
\text { kW }\end{array}$} & \multirow[b]{2}{*}{$\begin{array}{l}\text { Cost, } \\
\$\end{array}$} & \\
\hline & $\begin{array}{l}\text { Low } \\
\text { Side }\end{array}$ & $\begin{array}{l}\text { High } \\
\text { Side }\end{array}$ & & & & & & & \\
\hline \multicolumn{10}{|l|}{ Series } \\
\hline 1 & 1200 & 200 & 840 & $\$ 6,624$ & 200 & $\$ 1,330$ & 75 & $\$ 828$ & $\$ 10,451$ \\
\hline 2 & 300 & 200 & 300 & $\$ 2,520$ & 200 & $\$ 1,330$ & 75 & $\$ 828$ & $\$ 6,668$ \\
\hline 3 & & & & & 150 & $\$ 1,102$ & 75 & $\$ 828$ & $\$ 5,208$ \\
\hline 4 & 1200 & 150 & 810 & $\$ 6,396$ & 300 & $\$ 1,786$ & 75 & $\$ 828$ & $\$ 10,863$ \\
\hline 5 & & & & & 400 & $\$ 2,242$ & 75 & $\$ 828$ & $\$ 5,763$ \\
\hline 6 & & & & & 200 & $\$ 1,330$ & 75 & $\$ 828$ & $\$ 4,643$ \\
\hline 7 & 600 & 300 & 540 & $\$ 4,344$ & 300 & $\$ 1,786$ & 75 & $\$ 828$ & $\$ 8,966$ \\
\hline 8 & 200 & 200 & 240 & $\$ 2,064$ & 200 & $\$ 1,330$ & 75 & $\$ 828$ & $\$ 6,697$ \\
\hline \multicolumn{10}{|l|}{ Parallel } \\
\hline 1 & 800 & 75 & 525 & $\$ 4,230$ & 75 & $\$ 760$ & 37 & $\$ 426$ & $\$ 6,389$ \\
\hline 2 & 200 & 100 & 180 & $\$ 1,608$ & 100 & $\$ 874$ & 37 & $\$ 426$ & $\$ 4,526$ \\
\hline 3 & & & & & 100 & $\$ 874$ & 37 & $\$ 426$ & $\$ 4,212$ \\
\hline 4 & 800 & 200 & 600 & $\$ 4,800$ & 200 & $\$ 1330$ & 37 & $\$ 426$ & $\$ 7,529$ \\
\hline 5 & & & & & 300 & $\$ 1786$ & 37 & $\$ 426$ & $\$ 3,264$ \\
\hline 6 & & & & & 100 & $\$ 874$ & 37 & $\$ 426$ & $\$ 3,403$ \\
\hline 7 & 400 & 150 & 330 & $\$ 2,748$ & 150 & $\$ 1102$ & 37 & $\$ 426$ & $\$ 5,086$ \\
\hline 8 & 100 & 75 & 105 & $\$ 1,038$ & 75 & $\$ 760$ & 37 & $\$ 426$ & $\$ 4,327$ \\
\hline
\end{tabular}




\section{CONTACT}

Table 11. Life-cycle Costs to Evaluate

Battery-Pack Voltage Sensitivity in HEVs

\begin{tabular}{|c|c|c|c|c|}
\hline Case & $\begin{array}{l}\text { Initial } \\
\text { Drive } \\
\text { System } \\
\text { Cost, \$ }\end{array}$ & $\begin{array}{l}\text { Fuel } \\
\text { Cost, } \\
\$\end{array}$ & $\begin{array}{c}\text { Cost of } 4 \\
\text { Battery- } \\
\text { Pack } \\
\text { Changes, } \$\end{array}$ & $\begin{array}{l}\text { Life- } \\
\text { Cycle } \\
\text { Cost, \$ }\end{array}$ \\
\hline \multicolumn{5}{|l|}{ Series } \\
\hline 1 & $\$ 10,451$ & $\$ 6,654$ & $\$ 5,128$ & $\$ 22,243$ \\
\hline 2 & $\$ 6,668$ & $\$ 6,398$ & $\$ 6,412$ & $\$ 19,478$ \\
\hline 3 & $\$ 5,208$ & $\$ 5,139$ & $\$ 11,540$ & $\$ 21,887$ \\
\hline 4 & $\$ 10,863$ & $\$ 6,373$ & $\$ 5,128$ & $\$ 22,364$ \\
\hline 5 & $\$ 5,763$ & $\$ 6,346$ & $\$ 8,332$ & $\$ 20,442$ \\
\hline 6 & $\$ 4,643$ & $\$ 5,036$ & $\$ 8,332$ & $\$ 18,011$ \\
\hline 7 & $\$ 8,966$ & $\$ 6,527$ & $\$ 6,412$ & $\$ 21,905$ \\
\hline 8 & $\$ 6,697$ & $\$ 6,887$ & $\$ 8,332$ & $\$ 21,916$ \\
\hline \multicolumn{5}{|c|}{ Parallel } \\
\hline 1 & $\$ 6,389$ & $\$ 4,522$ & $\$ 3,848$ & $\$ 14,759$ \\
\hline 2 & $\$ 4,526$ & $\$ 9,148$ & $\$ 6,412$ & $\$ 20,086$ \\
\hline 3 & $\$ 4,212$ & $\$ 7,092$ & $\$ 11,540$ & $\$ 22,844$ \\
\hline 4 & $\$ 7,529$ & $\$ 4,677$ & $\$ 3,848$ & $\$ 16,054$ \\
\hline 5 & $\$ 3,264$ & $\$ 6,193$ & $\$ 4,168$ & $\$ 13,625$ \\
\hline 6 & $\$ 3,403$ & $\$ 5,756$ & $\$ 8,332$ & $\$ 17,491$ \\
\hline 7 & $\$ 5,086$ & $\$ 5,499$ & $\$ 3,204$ & $\$ 13,789$ \\
\hline 8 & $\$ 4,327$ & $\$ 7,246$ & $\$ 8,332$ & $\$ 19,905$ \\
\hline
\end{tabular}

\section{CONCLUSIONS}

1. Analysis of configuration and control fuel consumption penalties indicated that the series HEV Case 6 driven by the intermediate voltage motor with no boost converter was the best performer on the urban schedule. The parallel HEV Case 4 driven by the lowest voltage motor with the least number of batteries capable of delivering the required PNGV power was the best performer on the highway schedule. The parallel HEV Case 1 driven by the highest voltage motor with the least number of batteries was the best overall performer.

2. The battery pack in the series configuration consumes 2.6 times the energy in the parallel configuration. This will have an impact on its lifetime and possibly on battery replacement costs.

3. Drive system costs indicate that the parallel HEV Cases 5 and 6 with low and medium voltage motors are winners by over $\$ 800$ because they have no boost converter costs.

4. Fuel costs indicate that the parallel HEV Cases 1 and 4 with a boost converter and the least number of batteries capable of meeting PNGV requirements are winners regardless of the motor voltage levels.

5. Life-cycle costs indicate that the overall winner is the parallel HEV operating the lowest voltage motor with only 13 batteries connected in series and no boost converter.
John W. McKeever received the B.S. degree in physics from Case Institute of Technology, Cleveland, Ohio, and the M.S. and Ph.D. degrees in physics from the University of Tennessee, Knoxville. He has 39 years of work experience, serving in both technical and project management capacities. From 1960 to 1985, he developed uranium enrichment processes at the Oak Ridge Gaseous Diffusion Plant. From 1985 to the present, he has been involved in technology transfer and program development as part of the Engineering Technology Division, Oak Ridge National Laboratory (ORNL), at Oak Ridge, Tennessee. $\mathrm{He}$ is currently involved with the Power Electronics and Electric Machinery Research Center managing HEV research projects for DOE and collaborative projects to commercialize ORNL's inverter technology. John's e-mail address is mckeeverjw@ornl.gov.

\section{REFERENCES}

1. Y. Ikeda, J. Itsumi, and H. Funato, "The power loss of the PWM voltage-fed inverter," 1988 IEEE Power Electronics Specialists Conference, pp.277-283.

2. J. W. Lai, R. W. Young, and J. W. McKeever, "Efficiency Consideration of DC Link Soft-Switching Inverters for Motor Drive Applications," 1994 IEEE Power Electronics Specialists Conference, pp. 10031010.

3. T. E. Lipman, "The Cost of Manufacturing Electric Vehicle Drivetrains," Draft Report for the California Air Resources Board, Institute for Transportation Studies, University of California at Davis, April 1999.

\section{ACRONYMS}

AIPM - Automotive Integrated Power Module

ANL - Argonne National Laboratory

HEV - Hybrid Electric Vehicle

IC - Internal Combustion

PATHS - Performance Assessment Toolbox for Hybrid Systems

PNGV - Partnership for a New Generation of Vehicles

PVC - Polyvinyl chloride

SOC - State of Charge

SWRI Southwest Research Institute 